\title{
Morphological study of the human hyoid bone with three-dimensional CT images - Gender difference and age-related changes -
}

\author{
By
Kyoichi ITO $^{1,2 *}$, Satoshi ANDO ${ }^{3}$, Norihiko AKIBA ${ }^{1}$, Yuichi WATANABE ${ }^{1}$, Yasuo OKUYAMA ${ }^{4}$, Hisamoto MORIGUCHI ${ }^{4}$, Kohki YOSHIKAWA $^{4}$, Tsuneo TAKAHASHI ${ }^{5}$ and Morio SHIMADA ${ }^{4}$

\author{
'Department of Radiological Sciences, Graduate School of Medical Health Sciences, Komazawa University, 1-23-1 Komazawa, \\ Setagaya-ku, Tokyo, 154-8525, Japan \\ ${ }^{2}$ Department of Radiation, International Goodwill Hospital, 1-28-1 Nishigaoka, Izumi-ku, Yokohama, 245-0006, Japan \\ ${ }^{3}$ Department of Radiation, Yokohama City University Hospital, 3-9 Fukuura, Kanazawa-ku, Yokohama, 236-0004, Japan \\ ${ }^{4}$ Department of Radiological Sciences, Komazawa University, 1-23-1 Komazawa, Setagaya-ku, Tokyo, 154-8525, Japan \\ ${ }^{5}$ Department of Anatomy, Kanagawa Dental College, 82 Inaoka, Yokosuka, Kanagawa, 238-8580, Japan
}

- Received for Publication, October 23, 2012 -

Key words: CT, Three-dimensional image, hyoid bone, gender difference, age-related changes

\begin{abstract}
The human hyoid bone supports the base of the tongue and is involved in breathing, chewing, and swallowing as well as in the muscle movements associated with articulation. Accordingly it plays an important bone for a human to live. It is a very interesting organ also in multiple special area, including anatomy, mastication, swallowing, articulation, and also forensic medicine. In the morphological study of the human hyoid bone, there is a comparative anthropological research early in 1900, whereas the metrological research has been little reported later. We first used MDCT, and recorded each organic hyoid locus with a three-dimensional image for three-dimensional morphometry of gender differences, age-related changes, and the morphologic characters of the hyoid bone, and compared them with the results of our predecessors. By measuring the volume of the human hyoid bone, we identified gender difference at high rates, and estimated a certain level of ages based on the ossification at the junction area of the hyoid body and greater horns observed. Our results can be applied in the forensic medicine. By examining 600 cases, atypical horseshoes-shapes were found and the existence of the hyoid bone protrusion was demonstrated at high rates.
\end{abstract}

\section{Introduction}

In human anatomy, the hyoid bone is located immediately above the larynx at the height of the third cervical vertebra, and is consisted of the hyoid body, a pair of greater horns and a pair of lesser horns. The hyoid bone shows U-shaped in appearance, and is a small bone that is independent of the skull. To this small bone, ten different muscles that are classified in middle constrictor muscle of pharynx, glossus muscles and hyoid muscles are attached intricately. Stylohyoid ligament is attached to the lesser horn, the hyoid bone is suspended with long stylohyoid ligaments from the styloid process of the temporal bone of the outer skull base and maintains the position of the hyoid bone ${ }^{1,2)}$. The hyoid bone is phylogenetically equivalent to the structure of a branchial arch. The upper part of the body, lesser horns, and stylohyoid ligament are derived from the 2nd branchial cartilages, and the lower part of the body and greater horns are derived from the third branchial cartilages ${ }^{3)}$.

In the human hyoid bone, a mutation is often observed that is considered to be the result of ossification and atavisms ${ }^{4-6}$. Takada et al. compared it with the basic shape of a mammalian hyoid apparatus based on comparative anatomy with other mammalian mutations and reported that the styloid process and stylohyoid ligament is contained in the element of the anterior horn among the basal hyoid bone, anterior horn, and a dorsal horn which compose the mammalian hyoid apparatus. Furthermore, they discussed the changes to the intermediate ligament of the human hyoid anterior horn in relation to human evolution to human bipedal walking. Moreover, the human hyoid bone

\footnotetext{
* Correspondence author: Kyoichi Ito, Department of Radiation, International Goodwill Hospital, 1-28-1 Nishigaoka, Izumi-ku, Yokohama, $245-$ 0009, Japan. E-mail: ito-k@shinzen.jp
} 
supports the root of the tongue and stabilizes breathing, mastication, swallowing, and the muscle movement of articulation. Therefore, the human hyoid bone is an important bone for a human to live phylogenetically and functionally, and is a very interesting organ also across multiple special areas including anatomy, mastication, swallowing, articulation, and forensic medicine.

The morphological study of the human hyoid bone has been reported by Kamijo ${ }^{7)}$, Haga $^{8)}$, and Parson ${ }^{9}$. However, they are comparative anthropological researches conducted early in 1900, whereas the metrological research has been little reported thereafter. Moreover, there is no report which examined 600 cases like our study. Gender difference is observed in the size of the hyoid bone, and the hyoid bone of the human male is larger than that of the female ${ }^{10,11)}$. They were studied in dried skull or cadaver, and their morphological information is limited because it was difficult to do three-dimensional measurement of the hyoid bone with soft tissue or the human radiography with a ruler or slide calipers.

In the 21 st century, diagnostic imaging equipment such as CT and MRI has remarkably developed and multidetector row computed tomography (MDCT) became widespread recently. As a result, collection of the volume data in thin slice became available, and measurement accuracy on three-dimensional CT picture has been improved. Moreover, in Autopsy Imaging (Ai), diagnostic imaging equipment was proved to be effective, and it is widely introducing through the whole country. With this diagnostic equipment, it is easy to measure the volume, length, and angle of the hyoid bone. Moreover, in the hyoid bone, a stable image is obtained without influence of an artifact of a denture. In measurement of the hyoid bone, CT is more effective than MR because the hyoid bone is a bone. After the Great East Japan Earthquake, identification of the victims is relatively easy if they are found immediately after incidence of an earthquake disaster. However, the bodies found 1 or more years later are often difficult to identify with fingerprint matching and gender is often unknown because of severely decomposed bodies. When household and private goods were carried out to sea by at tsunami, the material to identify the body such as hairs necessary for a DNA test is fewer, and the body identification becomes difficult significantly. In the process of changes after death, the denture mold and bones remain to the last. It was covered in the media that the forensic odontology technique was useful in the present earthquake disaster. If a denture mold is matched, it is effective in identification of the body. If a denture mold is absent and gender is identified by the hyoid bone, the family may accept the body. We first observed and measured each part of the hyoid bone in vivo using MDCT to investigate gender difference, age-related changes, and three-dimensional morphological features, and compared with the results of predecessors for application of our results to forensic medicine.
Table 1. Age and sex distribution of study subjects

\begin{tabular}{lrrrrrr}
\hline \multirow{2}{*}{$\begin{array}{l}\text { Age Group } \\
\text { (Years) }\end{array}$} & \multirow{2}{*}{ Total } & $\%$ & \multicolumn{5}{c}{ Number of Cases } \\
\cline { 3 - 7 } & & & Males & $\%$ & Females & $\%$ \\
\hline $20-29$ & 39 & 6.5 & 20 & 51.3 & 19 & 48.7 \\
$30-39$ & 54 & 9.0 & 26 & 48.1 & 28 & 51.9 \\
$40-49$ & 73 & 12.2 & 38 & 52.1 & 35 & 47.9 \\
$50-59$ & 102 & 17.0 & 52 & 51.0 & 50 & 49.0 \\
$60-69$ & 129 & 21.5 & 73 & 56.6 & 56 & 43.4 \\
$70-79$ & 135 & 22.5 & 66 & 48.9 & 69 & 51.1 \\
$80-89$ & 64 & 10.7 & 35 & 54.7 & 29 & 45.3 \\
$90-99$ & 4 & 0.7 & 0 & 0.0 & 4 & 100.0 \\
Total & 600 & & 310 & & 290 & \\
\hline
\end{tabular}

\section{Materials and Methods}

We used the data of 600 cases (310 males aged 20 87 years, mean 59.7 years; 290 females aged 20 94 years, mean age 59.6 years) which performed head and neck CT in the International Goodwill Hospital for this study (Table 1). This study was approval by the Ethics Committees of the International Goodwill Hospital and the Komazawa University. Patient information was analyzed after strict anonymity. Image information was anonymized with the code linked to the original data, and was strictly kept in the hospital, and inhibited its carrying out. The numerical data was accumulated in the database after anonymity with the code linked to the original data.

The CT equipment which we used is 64 rows of Light Speed VCT (GE Healthcare Japan), and image parameters are tube voltage of $120 \mathrm{kV}$, tube current of auto $\mathrm{mA}$, and reconstruction interval of $0.625 \mathrm{~mm}$. Advantage Workstation ver4.4 (GE Healthcare Japan) was used for the three-dimensional image-processing equipment. The three-dimensional image of the hyoid bone was prepared first, and the distance, angle, and volume of each part of the hyoid bone were measured with the measurement tool software of Advantage Workstation at the field of view (FOV) of $13 \mathrm{~cm}$. As shown in Fig. 1, measurement included volume and 10 parameters of hyoid body major axis $\left(\mathrm{A}-\mathrm{A}^{\prime}\right)$, hyoid body minor axis $\left(\mathrm{B}-\mathrm{B}^{\prime}\right)$, hyoid body thickness $\left(C-C^{\prime}\right)$, right greater horn length $\left(D^{-} D^{\prime}\right)$, left greater horn length $\left(\mathrm{E}^{-} \mathrm{E}^{\prime}\right)$, the distance between right and left lesser horns $\left(\mathrm{F}-\mathrm{F}^{\prime}\right)$, the distance between right and left greater horn centers $\left(\mathrm{G}-\mathrm{G}^{\prime}\right)$, posterior distal distance between right and left greater horn (D-E), the angle made by the right greater horn and the hyoid body (GHI), and the angle made by the left greater horn and the hyoid body $\left(\mathrm{G}^{\prime} \mathrm{H}^{\prime} \mathrm{I}\right)$. In order to test statistical significance of gender differences, the measurement values of each parameter were tested by the F-test for equality of variance in the mean values of males and females. Student's t-test was selected when the variance was equal, and Welch's t-test was selected for unequal variance under statistical signifi- 


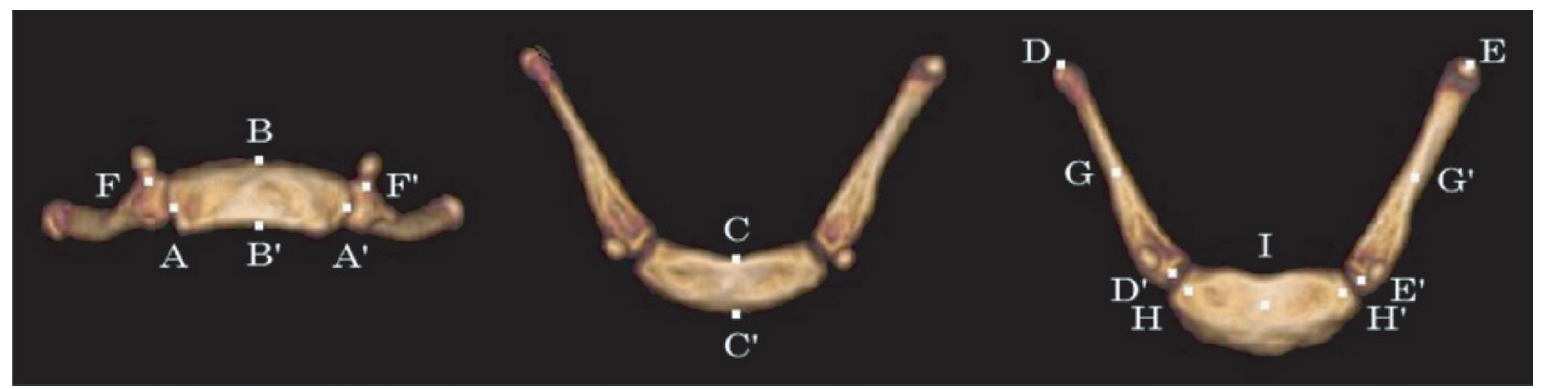

Fig. 1. Three views of the measurement points A-A', The major axis of the hyoid body. B-B', The minor axis of the hyoid body. C-C', The thickness of the hyoid body. D-D', The length of the right greater horn. E-E', The length of the left greater horn. F-F', The distance between right and left lesser horns. G-G', The distance between the centers of right and left greater horns. D-E, The Posterior distal distance between right and left greater horns. GHI, The angle made by the right greater horn and the hyoid body. G'H'I, The angle made by the left greater horn and the hyoid body.
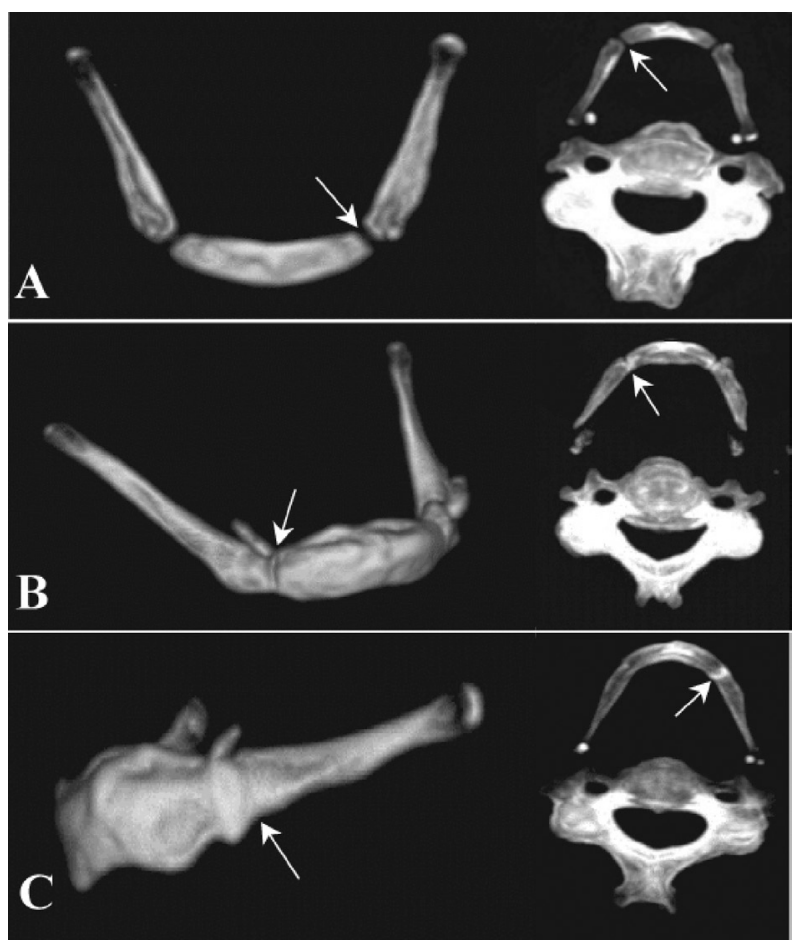

Fig. 2. The classification of changes in ossification at the connection between hyoid body and grater horns. The degree of ossification by aging and development of ossification of right and left bones were investigated after ossification was classified into the no fusion observed at the connection area (no fusion: Fig. 2. A, arrow), ossification commenced at the connection area but observed linear junction fusion alone (incomplete fusion: Fig. 2. B, allow), and the complete ossification without trace of fusion line (complete fusion: Fig. 2. C, allow)

cance level of $p<0.05$. Fig. 2 shows the classification of changes in ossification at the connection between hyoid body and greater horns. The degree of ossification by aging and development of ossification of right and left bones were investigated after ossification was classified into the no fusion observed at the connection area (no fusion), ossification commenced at the connection area but observed linear junction fusion alone (incomplete fusion), and the complete ossification without trace of fusion line (complete fusion). Moreover, the lingual-related morphological features of the hyoid bone are classified into the lingula developed at the center of upper peripheral hyoid body (development), the lingula that its scar was identified (scar), the lingula that was not identified (nothing) (Fig. 3 ), and their frequencies were examined.

As mentioned above, we investigated gender differences in the hyoid bone, the degrees of age-related changes and bone fusion of hyoid body and greater horn, and the lingula as the morphological characteristics of the hyoid bone.

\section{Results}

Measurement values and gender differences in the hyoid bone

The measurement values of the hyoid bone and the results of their significance test (t-test) for gender differences are shown in Table 2. In male and female mean values other than the angle made by the right and left hyoid bodies and greater horns, the statistically significant differences were detected. Their male mean values were higher than female values, and male maximum values did not exceed to female maximum values. On the contrary, female minimum values did not fall below the male minimum values.

In the parameters measured this time, the volume of the hyoid bone showed gender differences significantly. The number of the females who exceeded the male maximum values and the number of the males who are below the female minimum values are shown in Table 3. The 229 females (79.0\%) were below the minimum value 

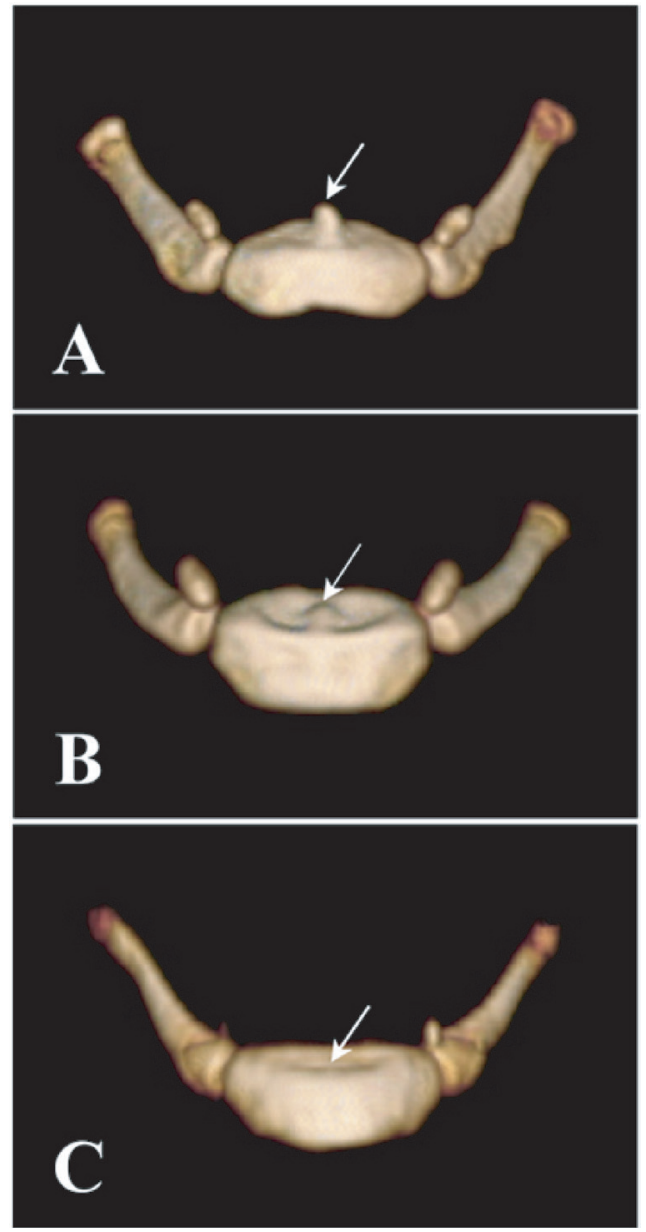

Fig. 3. The lingual-related morphological features of the hyoid bone are classified into the lingula developed at the center of upper peripheral hyoid body (development: Fig. 3. A, allow), the lingula that its scar was identified (scar: Fig. 3. B, allow), the lingula that was not identified (nothing: Fig. 3. C, allow) of $3.270 \mathrm{~cm}^{3}$ of the male hyoid volume, and 172 males $(55.5 \%)$ exceeded female maximum volume of $4.151 \mathrm{~cm}^{3}$. The means of the hyoid bone volume by ages are listed in Table 4. Changes in the volume by aging were not observed.

The only angle which was made by the right and left hyoid bodies and the greater horns did not show statistically significant differences. The mean values of the angle which was made by the right and left hyoid bodies and the greater horns are listed by ages in Table 5 . The significant differences by ages were not observed. Female right and left angles were 10 higher than the male angles.

\section{Age-related changes in the hyoid bone and bone fusion}

The connection between the hyoid body and greater horn develops ossification by aging. In our patients, the mean ages of ossification were male $45.9 \pm 15.8$ years and female $49.6 \pm 17.1$ years for bilateral non-fusion, male $58.2 \pm 14.9$ years and female $58.3 \pm 14.5$ years for unilateral fusion, and male $67.0 \pm 12.7$ years and female $67.8 \pm 14.3$ years for bilateral fusion. Moreover, in the unilateral ossification, left side ossification was significant in both sexes (Table 6). Although ossification generally commences in adults, the people who commenced ossification in the ages of 20 years were so fewer as $15 \%$ in males and $5.3 \%$ in females. The people of $50 \%$ and more observed ossification at the ages of 40 years and more in males and at the ages of 50 years and more in females. Development of ossification by aging was observed in approximate $80 \%$ of people after the age of 70 years in males and 80 years in females (Table 7). The changes in ossification at the connection between the hyoid bodies and the greater horns classified on the right and left bones separately and were shown in Table 8 . The degree of ossification development was classified on the right and left bones separately. The results showed the same age distribution with the results shown in Table 7. Table 9 shows the age distribution of the people who observed unilateral ossification. Only the left side ossification was significantly much more, but there was no significant deviation in age distribution.

Table 2. Measurements of hyoid bone

\begin{tabular}{|c|c|c|c|c|c|c|c|c|c|c|c|c|}
\hline & & $\begin{array}{l}\text { A-A' } \\
{[\mathrm{mm}]}\end{array}$ & $\begin{array}{l}\text { B-B' } \\
{[\mathrm{mm}]}\end{array}$ & $\begin{array}{l}\mathrm{C}-\mathrm{C}^{\prime} \\
{[\mathrm{mm}]}\end{array}$ & $\begin{array}{l}\text { D-D' } \\
{[\mathrm{mm}]}\end{array}$ & $\begin{array}{l}\text { E-E' } \\
{[\mathrm{mm}]}\end{array}$ & $\begin{array}{l}\mathrm{F}-\mathrm{F}^{\prime} \\
{[\mathrm{mm}]}\end{array}$ & $\begin{array}{l}\text { D-E } \\
{[\mathrm{mm}]}\end{array}$ & $\begin{array}{l}\text { G-G' } \\
{[\mathrm{mm}]}\end{array}$ & $\begin{array}{l}\mathrm{DHI} \\
{\left[^{\circ}\right]}\end{array}$ & $\begin{array}{l}\mathrm{D}^{\prime} \mathrm{H}^{\prime} \mathrm{I} \\
\left.{ }^{\circ}\right]\end{array}$ & $\begin{array}{l}\text { Volume } \\
{\left[\mathrm{cm}^{3}\right]}\end{array}$ \\
\hline \multirow[t]{4}{*}{ Males } & Mean & 27.67 & 9.47 & 7.27 & 34.17 & 33.57 & 28.2 & 48.57 & 38.77 & 135.7 & $135.0_{7}$ & 4.3087 \\
\hline & SD & 2.4 & 1.4 & 1.1 & 2.8 & 2.8 & 2.3 & 7.0 & 3.7 & 7.2 & 7.7 & 0.664 \\
\hline & Max & 36.6 ** & $16.0 * *$ & $10.5 * *$ & 44.9 ** & 43.1 ** & $37.8 * *$ & 69.2 ** & 48.6 ** & $155.3 *$ & $156.3 *$ & 7.159 \\
\hline & Min & 20.6 & 6.3 & 4.6 & 27.6 & 26.9 & 20.1 & 32.5 & 30.5 & 114.6 & 113.9 & 3.270 \\
\hline \multirow[t]{4}{*}{ Femails } & Mean & $22.0\rfloor$ & 7.8 」 & $5.9\rfloor$ & $30.0\rfloor$ & 29.6 & 24.0 & $42.2\rfloor$ & 33.0 ] & 136.4 & 136.0 ] & $2.949\rfloor$ \\
\hline & $\mathrm{SD}$ & 2.2 & 1.2 & 1.1 & 2.5 & 2.5 & 1.9 & 5.3 & 2.8 & 6.8 & 7.2 & 0.449 \\
\hline & Max & 27.9 & 11.9 & 8.8 & 36.9 & 36.7 & 28.9 & 57.8 & 40.9 & 157.6 & 159.9 & 4.151 \\
\hline & Min & 16.0 & 4.8 & 3.0 & 20.0 & 23.6 & 18.3 & 27.9 & 24.9 & 119.7 & 116.8 & 1.893 \\
\hline
\end{tabular}

$\mathrm{p}>0.05 * \quad \mathrm{p}<0.05 * *$ 
Table 3. Relationship between the maximum and minimum values of each measurement point

\begin{tabular}{|c|c|c|c|c|c|c|}
\hline & $\begin{array}{l}\text { Minimum Value } \\
\text { of Male }\end{array}$ & $\begin{array}{l}\text { The Number of Females } \\
\text { are Smaller than the } \\
\text { Minimum Value of Male }\end{array}$ & $\%$ & $\begin{array}{l}\text { Maximum Value } \\
\text { of Female }\end{array}$ & $\begin{array}{l}\text { The Number of Males } \\
\text { are Greater than the } \\
\text { Maximum Value of Male }\end{array}$ & $\%$ \\
\hline $\mathrm{A}-\mathrm{A}^{\prime}[\mathrm{mm}]$ & 20.6 & 89 & 30.7 & 27.9 & 128 & 41.3 \\
\hline $\mathrm{B}-\mathrm{B}^{\prime}[\mathrm{mm}]$ & 6.3 & 35 & 12.1 & 11.9 & 15 & 4.8 \\
\hline $\mathrm{C}-\mathrm{C}^{\prime}[\mathrm{mm}]$ & 4.6 & 38 & 13.1 & 8.8 & 29 & 9.4 \\
\hline $\mathrm{E}^{\wedge} \mathrm{E}^{\prime}[\mathrm{mm}]$ & 26.9 & 43 & 14.8 & 36.7 & 44 & 14.2 \\
\hline $\mathrm{F}-\mathrm{F}^{\prime}[\mathrm{mm}]$ & 20.1 & 11 & 3.8 & 28.9 & 112 & 36.1 \\
\hline $\mathrm{D}-\mathrm{E}[\mathrm{mm}]$ & 32.5 & 10 & 3.4 & 57.8 & 31 & 10.0 \\
\hline $\mathrm{G}-\mathrm{G}^{\prime}[\mathrm{mm}]$ & 30.5 & 61 & 21.0 & 40.9 & 92 & 29.7 \\
\hline $\mathrm{GHI}\left[{ }^{\circ}\right]$ & 114.6 & 0 & 0.0 & 157.6 & 0 & 0.0 \\
\hline $\mathrm{G}^{\prime} \mathrm{H}^{\prime} \mathrm{I}\left[^{\circ}\right]$ & 113.9 & 0 & 0.0 & 159.9 & 0 & 0.0 \\
\hline Volume $\left[\mathrm{cm}^{3}\right]$ & 3.27 & 229 & 79.0 & 4.151 & 172 & 55.5 \\
\hline
\end{tabular}

Table 4. The average Volume of hyoid bone by age in males and females

\begin{tabular}{lccccc}
\hline \multirow{2}{*}{$\begin{array}{l}\text { Age Group } \\
\text { (Years) }\end{array}$} & \multicolumn{2}{c}{ Males } & & \multicolumn{2}{c}{ Females } \\
\cline { 2 - 3 } \cline { 5 - 6 } & Average & SD & & Average & SD \\
\hline 20-29 & 4.450 & 0.701 & 2.903 & 0.486 \\
$30-39$ & 4.555 & 0.565 & 2.933 & 0.373 \\
$40-49$ & 4.376 & 0.530 & 2.923 & 0.496 \\
$50-59$ & 4.410 & 0.677 & 2.932 & 0.461 \\
$60-69$ & 4.220 & 0.629 & 2.893 & 0.461 \\
$70-79$ & 4.199 & 0.616 & 2.980 & 0.460 \\
$80-89$ & 4.211 & 0.901 & 3.094 & 0.387 \\
$90-99$ & - & - & 2.946 & 0.336 \\
Total & 4.308 & 0.664 & 2.949 & 0.449 \\
\hline
\end{tabular}

\section{Morphological characteristics of the hyoid bone}

The appearance of majority of the hyoid bone shows U-shape. In the present study, there were patients who showed the horseshoe-shape, not U-shape (Fig. 4). The hyoid bone of which posterior distal distance (D-E) of right and left greater horns was longer than the distance
$\left(\mathrm{G}-\mathrm{G}^{\prime}\right)$ between measurement site and the center of right and left greater horns was defined as a U-shape, and the hyoid bone of which distance was shorter was defined as a horseshoe-shape. This horseshoe-shape is the shape we first observed and has never been described in the published papers. The horseshoe-shaped hyoid bone was very few, and approximate $90 \%$ or more of the hyoid bones showed a U-shape regardless of gender differences and ages (Table 10).

The frequency of the lingula in the center of upper peripheral hyoid bodies is shown in Table 11. Lingula at the hyoid body was clearly observed in 174 males $(56.1 \%)$ and 161 females (55.5\%). If the scar of lingula is included, the lingula was observed in 283 males (91.3\%) and 261 females $(90.0 \%)$. Existence of lingula was identified regardless of gender differences.

\section{Discussion}

Previously, we thought that the artifact may exert a serious influence on the analysis of three-dimensional data of the hyoid body obtained by MDCT.

Table 5. Unilateral Angle of hyoid bone in males and females

\begin{tabular}{|c|c|c|c|c|c|c|c|c|}
\hline \multirow{2}{*}{$\begin{array}{l}\text { Age Group } \\
\text { (Years) }\end{array}$} & \multicolumn{4}{|c|}{ Males } & \multicolumn{4}{|c|}{ Females } \\
\hline & Right Side Angle & SD & Left Side Angle & SD & Right Side Angle & SD & Left Side Angle & $\mathrm{SD}$ \\
\hline $20-29$ & 133.4 & 6.1 & 131.9 & 7.0 & 137.2 & 6.5 & 136.3 & 8.3 \\
\hline $30-39$ & 134.8 & 7.0 & 133.2 & 9.3 & 135.5 & 7.4 & 135.1 & 8.6 \\
\hline $40-49$ & 133.9 & 6.4 & 133.6 & 7.9 & 136.4 & 5.5 & 136.3 & 6.6 \\
\hline $50-59$ & 137.4 & 7.7 & 135.4 & 7.7 & 135.7 & 6.9 & 134.8 & 6.6 \\
\hline $60-69$ & 135.9 & 7.2 & 136.3 & 7.6 & 136.1 & 6.9 & 136.0 & 7.2 \\
\hline $70-79$ & 135.3 & 7.6 & 134.6 & 6.9 & 136.7 & 7.5 & 135.8 & 7.2 \\
\hline $80-89$ & 137.8 & 7.1 & 136.9 & 7.7 & 137.6 & 6.4 & 138.4 & 6.9 \\
\hline 90-99 & - & - & - & - & 136.5 & 7.7 & 140.3 & 2.6 \\
\hline Total & 135.7 & 7.2 & 135.0 & 7.7 & 136.4 & 6.8 & 136.0 & 7.2 \\
\hline
\end{tabular}


However, it was found that stable three-dimensional MDCT data can be obtained without influence of the artifact such as oral denture and implant and also without lack of X-ray doses which determine quality of imaging because of the anatomical spatial location of the hyoid bone. MDCT visualizes CT values alone of the bone and the peripheral soft tissues can be erased, so that the bone tissue of the hyoid bone alone is accurately displayed.

In our method of the three-dimensional measurement with MDCT, the hyoid bone with soft tissue collected from cadaver can be measured using a slide calipers, and accurate measurement by two-dimensional radiography is available.

\section{Gender differences of the hyoid bone}

Among the parameters of the hyoid bone measured, the volume of the hyoid bone showed most significant gender differences (Table 2). The people whose volumes were less than the minimal value of $3.270 \mathrm{~cm}^{3}$ of male hyoid

Table 6. Mean age of hyoid bone fusion in males and females

\begin{tabular}{lrcc}
\hline & Case No & Mean Age (Years) & SD \\
\hline Males & & & \\
Bilateral non-fusion & 89 & 45.9 & 15.8 \\
Unilateral fusion & 43 & 58.2 & 14.9 \\
$\quad$ Right side fusion & 9 & 66.2 & 14.0 \\
$\quad$ Left side fusion & 34 & 56.1 & 14.6 \\
Bilateral fusion & 178 & 67.0 & 12.7 \\
Total & 310 & 59.7 & 16.7 \\
Females & & & \\
Bilateral non-fusion & 114 & 49.6 & 17.1 \\
Unilateral fusion & 32 & 58.3 & 14.5 \\
$\quad$ Right side fusion & 10 & 54.4 & 16.9 \\
$\quad$ Left side fusion & 22 & 60.0 & 13.3 \\
Bilateral fusion & 144 & 67.8 & 14.3 \\
Total & 290 & 59.6 & 17.6 \\
\hline
\end{tabular}

bone were 229 females (79.0\%), and 172 males (55.5\%) exceeded the maximum volume of $4.151 \mathrm{~cm}^{3}$ of female hyoid bone. It can be estimated that the human whose volume of the hyoid bone is less than $3.270 \mathrm{~cm}^{3}$ is a female with a probability of approximate $79.0 \%$, and the human whose volume is more than $4.151 \mathrm{~cm}^{3}$ is a male with a probability of approximate $55.5 \%$ (Table 3 ). In the mean volume of the hyoid bone by aging, the changes in the volume by aging was not observed, which suggests that formation of the hyoid bone was completed in adults, and the morphology is little changed by aging thereafter (Table 4).

As far as we investigated, there were no reports which measured the volume of the hyoid bone. The measurement using a three-dimensional CT imaging is simple and has high precision, and it can be applied effectively to the forensic medicine. Among the parameters measured, it was only the angle made by the right and left hyoid bodies and greater horns that did not detect statistically significant differences. Kamijo made same conclusion with us that the angle in females was higher than the angle in males without statistical differences ${ }^{7}$. In our study, significant differences in the angle were not observed in gender differences and ages (Table 5).

The unknown dead bodies that deserted and soft tissues were decomposed are difficult to identify their gender. In such case, bone, tooth, and hair are often used for forensics examination. Bone retains the original form for a long period of time. The authors thought that measurement of the hyoid bone might be an effective tool for gender estimation. However, it might have a high risk to estimate gender based on the measurement data of the hyoid bone. In our present study, statistically significant differences were observed in a majority of parameters, but we could not find the standard values for reliable classification of gender differences. Size and thickness of the greater horn might be related. The hyoid bone was not changed by aging. Therefore, measurement of the volume will be most

Table 7. Fusion of hyoid bone in males and females

\begin{tabular}{|c|c|c|c|c|c|c|c|c|c|c|c|c|}
\hline \multirow{3}{*}{$\begin{array}{l}\text { Age Group } \\
\text { (Years) }\end{array}$} & \multicolumn{6}{|c|}{ Males } & \multicolumn{6}{|c|}{ Females } \\
\hline & \multicolumn{2}{|c|}{$\begin{array}{c}\text { Bilateral } \\
\text { Non-Fusion }\end{array}$} & \multicolumn{2}{|c|}{$\begin{array}{l}\text { Unilateral } \\
\text { Fusion }\end{array}$} & \multicolumn{2}{|c|}{$\begin{array}{l}\text { Bilateral } \\
\text { Fusion }\end{array}$} & \multicolumn{2}{|c|}{$\begin{array}{c}\text { Bilateral } \\
\text { Non-Fusion }\end{array}$} & \multicolumn{2}{|c|}{$\begin{array}{l}\text { Unilateral } \\
\text { Fusion }\end{array}$} & \multicolumn{2}{|c|}{$\begin{array}{l}\text { Bilateral } \\
\text { Fusion }\end{array}$} \\
\hline & No & $\%$ & No & $\%$ & No & $\%$ & No & $\%$ & No & $\%$ & No & $\%$ \\
\hline $20-29$ & 17 & 85.0 & 1 & 5.0 & 2 & 10.0 & 18 & 94.7 & 0 & 0.0 & 1 & 5.3 \\
\hline $30-39$ & 19 & 73.1 & 4 & 15.4 & 3 & 11.5 & 17 & 60.7 & 4 & 14.3 & 7 & 25.0 \\
\hline $40-49$ & 15 & 39.5 & 9 & 23.7 & 14 & 36.8 & 22 & 62.9 & 6 & 17.1 & 7 & 20.0 \\
\hline $50-59$ & 19 & 36.5 & 6 & 11.5 & 27 & 51.9 & 19 & 38.0 & 7 & 14.0 & 24 & 48.0 \\
\hline $60-69$ & 13 & 17.8 & 14 & 19.2 & 46 & 63.0 & 19 & 33.9 & 6 & 10.7 & 31 & 55.4 \\
\hline $70-79$ & 5 & 7.6 & 7 & 10.6 & 54 & 81.8 & 17 & 24.6 & 6 & 8.7 & 46 & 66.7 \\
\hline $80-89$ & 1 & 2.9 & 2 & 5.7 & 32 & 91.4 & 2 & 6.9 & 3 & 10.3 & 24 & 82.8 \\
\hline $90-99$ & 0 & 0.0 & 0 & 0.0 & 0 & 0.0 & 0 & 0.0 & 0 & 0.0 & 4 & 100.0 \\
\hline Total & 89 & 28.7 & 43 & 13.9 & 178 & 57.4 & 114 & 39.3 & 32 & 11 & 144 & 49.7 \\
\hline
\end{tabular}


Table 8. Classify degree of bone fusion

\begin{tabular}{|c|c|c|c|c|c|c|c|c|c|c|c|c|}
\hline \multirow{4}{*}{$\begin{array}{l}\text { Age Group } \\
\text { (Years) }\end{array}$} & \multicolumn{12}{|c|}{ Right Side } \\
\hline & \multicolumn{6}{|c|}{ Males } & \multicolumn{6}{|c|}{ Females } \\
\hline & \multicolumn{2}{|c|}{ No Fusion } & \multicolumn{2}{|c|}{$\begin{array}{l}\text { Incomplete } \\
\text { Fusion }\end{array}$} & \multicolumn{2}{|c|}{$\begin{array}{l}\text { Complete } \\
\text { Fusion }\end{array}$} & \multicolumn{2}{|c|}{ No Fusion } & \multicolumn{2}{|c|}{$\begin{array}{l}\text { Incomplete } \\
\text { Fusion }\end{array}$} & \multicolumn{2}{|c|}{$\begin{array}{l}\text { Complete } \\
\text { Fusion }\end{array}$} \\
\hline & No & $\%$ & No & $\%$ & No & $\%$ & No & $\%$ & No & $\%$ & No & $\%$ \\
\hline $20-29$ & 18 & 90.0 & 1 & 5.0 & 1 & 5.0 & 18 & 94.7 & 0 & 0.0 & 1 & 5.3 \\
\hline $30-39$ & 23 & 88.5 & 1 & 3.8 & 2 & 7.7 & 18 & 64.3 & 2 & 7.1 & 8 & 28.6 \\
\hline $40-49$ & 22 & 57.9 & 4 & 10.5 & 12 & 31.6 & 27 & 77.1 & 2 & 5.7 & 6 & 17.1 \\
\hline $50-59$ & 25 & 48.1 & 9 & 17.3 & 18 & 34.6 & 24 & 48.0 & 11 & 22.0 & 15 & 30.0 \\
\hline $60-69$ & 24 & 32.9 & 11 & 15.1 & 38 & 52.1 & 23 & 41.1 & 7 & 12.5 & 26 & 46.4 \\
\hline $70-79$ & 8 & 12.1 & 15 & 22.7 & 43 & 65.2 & 22 & 31.9 & 7 & 10.1 & 40 & 58.0 \\
\hline $80-89$ & 3 & 8.6 & 5 & 14.3 & 27 & 77.1 & 4 & 13.8 & 0 & 0.0 & 25 & 86.2 \\
\hline 90-99 & 0 & - & 0 & - & 0 & - & 0 & 0.0 & 1 & 25.0 & 3 & 75.0 \\
\hline Total & 123 & 39.7 & 46 & 14.8 & 141 & 45.5 & 136 & 46.9 & 30 & 10.3 & 124 & 42.8 \\
\hline \multirow{4}{*}{$\begin{array}{l}\text { Age Group } \\
\text { (Years) }\end{array}$} & \multicolumn{12}{|c|}{ Left Side } \\
\hline & \multicolumn{6}{|c|}{ Males } & \multicolumn{6}{|c|}{ Females } \\
\hline & \multicolumn{2}{|c|}{ No Fusion } & \multicolumn{2}{|c|}{$\begin{array}{l}\text { Incomplete } \\
\text { Fusion }\end{array}$} & \multicolumn{2}{|c|}{$\begin{array}{l}\text { Complete } \\
\text { Fusion }\end{array}$} & \multicolumn{2}{|c|}{ No Fusion } & \multicolumn{2}{|c|}{$\begin{array}{l}\text { Incomplete } \\
\text { Fusion }\end{array}$} & \multicolumn{2}{|c|}{$\begin{array}{l}\text { Complete } \\
\text { Fusion }\end{array}$} \\
\hline & No & $\%$ & No & $\%$ & No & $\%$ & No & $\%$ & No & $\%$ & No & $\%$ \\
\hline $20-29$ & 17 & 85.0 & 1 & 5.0 & 2 & 10.0 & 18 & 94.7 & 1 & 5.3 & 0 & 0.0 \\
\hline $30-39$ & 19 & 73.1 & 4 & 15.4 & 3 & 11.5 & 20 & 71.4 & 2 & 7.1 & 6 & 21.4 \\
\hline $40-49$ & 17 & 44.7 & 9 & 23.7 & 12 & 31.6 & 23 & 65.7 & 4 & 11.4 & 8 & 22.9 \\
\hline $50-59$ & 19 & 36.5 & 7 & 13.5 & 26 & 50.0 & 21 & 42.0 & 6 & 12.0 & 23 & 46.0 \\
\hline $60-69$ & 16 & 21.9 & 15 & 20.5 & 42 & 57.5 & 21 & 37.5 & 11 & 19.6 & 24 & 42.9 \\
\hline $70-79$ & 9 & 13.6 & 13 & 19.7 & 44 & 66.7 & 18 & 26.1 & 9 & 13.0 & 42 & 60.9 \\
\hline $80-89$ & 1 & 2.9 & 4 & 11.4 & 30 & 85.7 & 3 & 10.3 & 1 & 3.4 & 25 & 86.2 \\
\hline 90-99 & 0 & - & 0 & - & 0 & - & 0 & 0.0 & 1 & 25.0 & 3 & 75.0 \\
\hline Total & 98 & 31.6 & 53 & 17.1 & 159 & 51.3 & 124 & 42.8 & 35 & 12.1 & 131 & 45.2 \\
\hline
\end{tabular}

Table 9. Unilateral fusion of hyoid bone in males and females

\begin{tabular}{lccccc}
\hline $\begin{array}{l}\text { Age Group } \\
\text { (Years) }\end{array}$ & \multicolumn{2}{c}{ Males } & & \multicolumn{2}{c}{ Females } \\
\cline { 2 - 3 } \cline { 5 - 6 } & $\begin{array}{c}\text { Right Side } \\
\text { Fusion }\end{array}$ & $\begin{array}{c}\text { Left Side } \\
\text { Fusion }\end{array}$ & & $\begin{array}{c}\text { Right Side } \\
\text { Fusion }\end{array}$ & $\begin{array}{c}\text { Left Side } \\
\text { Fusion }\end{array}$ \\
\hline $20-29$ & 0 & 1 & & 0 & 0 \\
$30-39$ & 0 & 4 & & 3 & 1 \\
$40-49$ & 2 & 7 & & 1 & 5 \\
$50-59$ & 0 & 6 & & 2 & 5 \\
$60-69$ & 3 & 11 & & 2 & 4 \\
$70-79$ & 4 & 3 & & 1 & 5 \\
$80-89$ & 0 & 2 & & 1 & 2 \\
$90-99$ & 0 & 0 & & 0 & 0 \\
Total & 9 & 34 & & 10 & 22 \\
\hline
\end{tabular}

sensitive for estimation of gender differences in the hyoid bone having complicated form. We will clarify the morphological characteristics related to the size of the hyoid bone in the future.

\section{Changes by aging and ossification of the hyoid bone}

Ossification of the hyoid bone occurs at the connection between hyoid body and greater horns. Ossification commences in adults, and develops by aging ${ }^{12,13)}$. In our subjects, bilateral complete fusion was observed in the males aged 50 years and the females aged 60 years with a probability of $50 \%$ and more, showing that complete fusion in females was delayed for 10 years compared with males. In the population over 80 years of age, a probability is $80 \%$ or more in both sexes. Age can be estimated to a certain degree based on the observation of ossified condition.

In our study, there were significantly many people whose left hyoid bone alone was ossificated regardless of gender differences and ages. The muscles adhered to the 

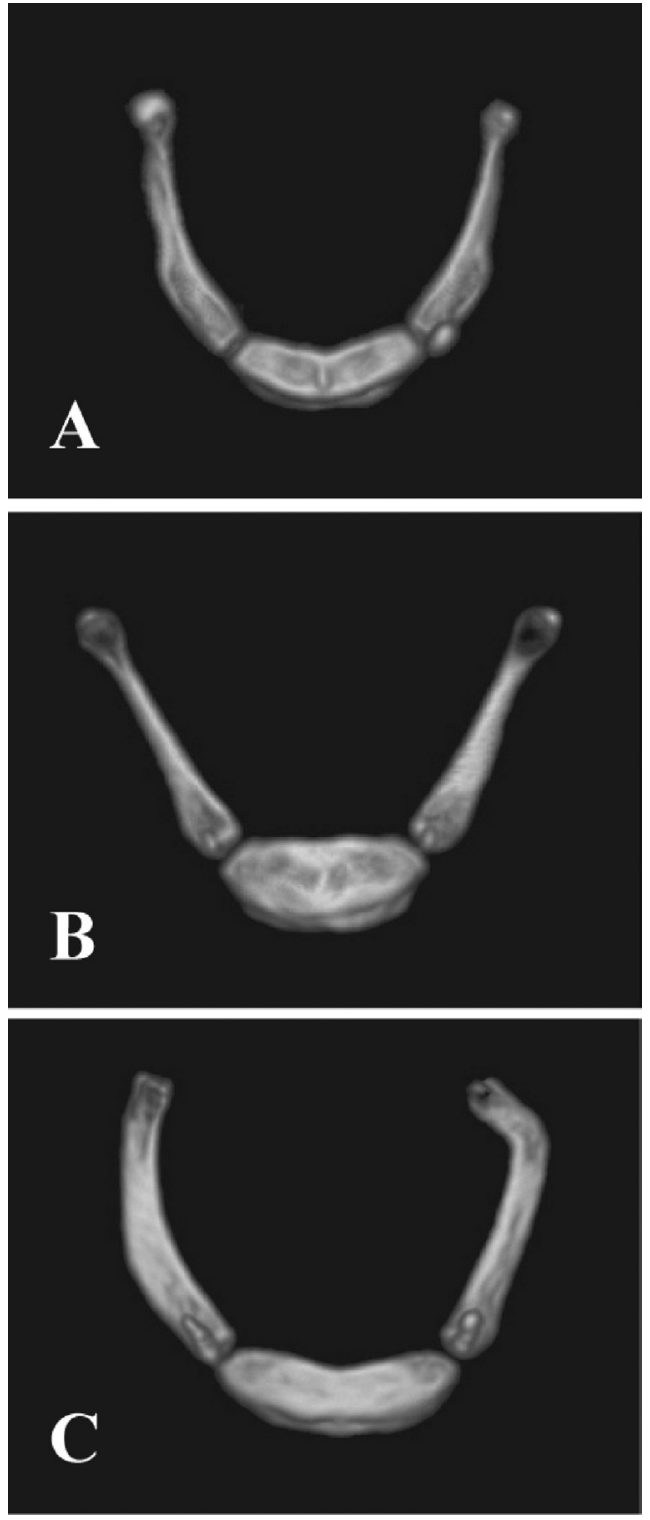

Fig. 4. The hyoid bone of which posterior distal distance (D-E) of right and left greater horns was longer than the distance (G-G') between measurement site and the center of right and left greater horns was defined as a U-shape (A, B), and the hyoid bone of which distance was shorter was defined as a horseshoe-shape (C).

hyoid bone have origin stops in upper and lower large area, and most of them are concentrated in the hyoid body and the connection between hyoid body and greater horns. These lines are classified into suprahyoid muscle and infrahyoid muscle groups. The suprahyoid muscle is known as opening line and the infrahyoid muscle as swallowing source. Moreover, the line adhered to the hyoid bone has origin stops in the cranium, the lower jaw, sternum, and shoulder blade, and the hyoid bone plays an important role in maintaining the commutative spatial relationship of the bones of the upper body ${ }^{3}$. In this study, it is difficult to explain the reason why the ossification of left hyoid bone alone was significant. The authors presume that there are many right-handed individuals among Japanese people, the left jaw is used predominantly for the peculiarity at the time of mastication, or the balance and motor action of the upper body might be involved in the causes, but further research is required in the future. It would be a really challenging question. In the future, ages will be estimated using CT image together with the histological findings of the soft tissues at the connection between greater horns and hyoid body and the results of age-related changes compared with CT image.

The hyoid bone has U-shape formed with the forefinger and thumb, and located under lower jawbone, immediately above the pharynx, at the front third cervical vertebrae and at the position of the third molar tooth. Appearance of all hyoid bones does not always show U-shape, and a tightly angled V-shape is included in them ${ }^{14)}$. In our study, there were the people having horseshoe-shape neither belonged to U-shape nor V-shape in $4.2 \%$ of the males and $2.1 \%$ of the females. The connection between hyoid body and greater horns will be ossified by aging, and the angle will be changed. However, the greater horns tended to curve strongly towards the rear inner side in the people having a horseshoe-shape. There were few people who showed horseshoe-shape, and no deviation was observed in their age distribution. It is presumed that asymmetric or the horseshoe-shaped hyoid bone may show any abnormal findings. The population of the hyoid bones examined in this study was so many 600 examples, which contributed to the detection of very rare the horseshoe-shaped hyoid bone.

\section{Hyoid projection}

A small process is observed in the hyoid bone at the center of upper peripheral hyoid body. Some process grows well. Large process of the major axis of $5.5 \mathrm{~mm}$ was found in this study. Kamijo gave a name of lingula to this process ${ }^{15)}$. Parson described that such rudimentary lingula belongs to the normal process, the site of incidence is same with the point where thyrolingual duct reaches the hyoid bone, and that this process is the residue of the thyrolingual duct ${ }^{9}$. These processes were found in $65 \%$ and $55.9 \%$ of Japanese hyoid bones including a rudimentary process, and in $62.0 \%$ of South Chinese reported by Kamijo, Haga, and Kinbara, respectively. In our study, clear lingula was observed in 174 males (56.1\%) and 161 females $(55.5 \%)$. If rudimentary lingula was included together, lingula was observed in 283 males (91.3\%) and 261 females (90.0\%), and existence of lingula was identified regardless of gender differences (Table 11). They were found to be slightly different with the results of Kamijo and others. Since we analyzed the hyoid bone in three dimensions, our detection rate of lingula might have been higher than the results obtained by the method to observe the hyoid bone collected from body donation. 
Table 10. Shape of the hyoid bone (Horseshoe-shaped or trapezoidal)

\begin{tabular}{|c|c|c|c|c|c|c|c|c|}
\hline \multirow{2}{*}{$\begin{array}{l}\text { Age Group } \\
\text { (Years) }\end{array}$} & \multicolumn{4}{|c|}{ Males } & \multicolumn{4}{|c|}{ Females } \\
\hline & $\mathrm{D}-\mathrm{E}>\mathrm{G}-\mathrm{G}^{\prime}$ & $\%$ & $\mathrm{D}-\mathrm{E}<\mathrm{G}-\mathrm{G}^{\prime}$ & $\%$ & $\mathrm{D}-\mathrm{E}>\mathrm{G}^{-\mathrm{G}^{\prime}}$ & $\%$ & $\mathrm{D}-\mathrm{E}<\mathrm{G}-\mathrm{G}^{\prime}$ & $\%$ \\
\hline $20-29$ & 19 & 95.0 & 1 & 5.0 & 19 & 100.0 & 0 & 0.0 \\
\hline $30-39$ & 24 & 92.3 & 2 & 7.7 & 27 & 96.4 & 1 & 3.6 \\
\hline $40-49$ & 38 & 100.0 & 0 & 0.0 & 35 & 100.0 & 0 & 0.0 \\
\hline $50-59$ & 51 & 98.1 & 1 & 1.9 & 50 & 100.0 & 0 & 0.0 \\
\hline $60-69$ & 69 & 94.5 & 4 & 5.5 & 55 & 98.2 & 1 & 1.8 \\
\hline $70-79$ & 64 & 97.0 & 2 & 3.0 & 66 & 95.7 & 3 & 4.3 \\
\hline 80-89 & 32 & 91.4 & 3 & 8.6 & 28 & 96.6 & 1 & 3.4 \\
\hline 90-99 & 0 & 0.0 & 0 & & 4 & 100.0 & 0 & 0.0 \\
\hline Total & 297 & 95.8 & 13 & 4.2 & 284 & 97.9 & 6 & 2.1 \\
\hline
\end{tabular}

D-E > G-G': Trapezoidal

$\mathrm{D}-\mathrm{E}<\mathrm{G}-\mathrm{G}^{\prime}$ : Horseshoe-shaped

Table 11. Presence or absence of hyoid bone protrusion

\begin{tabular}{|c|c|c|c|c|c|c|c|c|c|c|c|c|}
\hline \multirow{3}{*}{$\begin{array}{l}\text { Age Group } \\
\text { (Years) }\end{array}$} & \multicolumn{6}{|c|}{ Males } & \multicolumn{6}{|c|}{ Females } \\
\hline & \multicolumn{2}{|c|}{ Development } & \multicolumn{2}{|c|}{ Scar } & \multicolumn{2}{|c|}{ Nothing } & \multicolumn{2}{|c|}{ Development } & \multicolumn{2}{|c|}{ Scar } & \multicolumn{2}{|c|}{ Nothing } \\
\hline & No & $\%$ & No & $\%$ & No & $\%$ & No & $\%$ & No & $\%$ & No & $\%$ \\
\hline $20-29$ & 10 & 50.0 & 8 & 40.0 & 2 & 10.0 & 14 & 73.7 & 5 & 26.3 & 0 & 0.0 \\
\hline $30-39$ & 18 & 69.2 & 7 & 26.9 & 1 & 3.8 & 17 & 60.7 & 7 & 25.0 & 4 & 14.3 \\
\hline $40-49$ & 23 & 60.5 & 10 & 26.3 & 5 & 13.2 & 20 & 57.1 & 12 & 34.3 & 3 & 8.6 \\
\hline $50-59$ & 30 & 57.7 & 20 & 38.5 & 2 & 3.8 & 29 & 58.0 & 13 & 26.0 & 8 & 16.0 \\
\hline $60-69$ & 42 & 57.5 & 23 & 31.5 & 8 & 11.0 & 30 & 53.6 & 24 & 42.9 & 2 & 3.6 \\
\hline $70-79$ & 30 & 45.5 & 30 & 45.5 & 6 & 9.1 & 35 & 50.7 & 26 & 37.7 & 8 & 11.6 \\
\hline $80-89$ & 21 & 60.0 & 11 & 31.4 & 3 & 8.6 & 15 & 51.7 & 10 & 34.5 & 4 & 13.8 \\
\hline $90-99$ & 0 & - & 0 & - & 0 & - & 1 & 25.0 & 3 & 75.0 & 0 & 0.0 \\
\hline Total & 174 & 56.1 & 109 & 35.2 & 27 & 8.7 & 161 & 55.5 & 100 & 34.5 & 29 & 10.0 \\
\hline
\end{tabular}

Description of lingula has not been found in any morphological papers and anatomy guidebook after Parson et al reported in 1909. In our study, lingula was identified in the people of $90.0 \%$ and more. The authors suggest that such existence of lingula is surely the morphological characteristics of the hyoid bone, not the pathologic phenomenon of the hyoid bone, and should be described in the anatomy guidebook in the future.

The forensic odontology technique to use dental records is known to be effective for identification of dead body, which was already proved at the work of victim's body identification in the Great East Japan Earthquake. However, the death toll exceeded 15,000 people, and 3000 or more people are still missing. The body identification for returning the dead body to the family has become extremely difficult. The in-vivo body information used for body identification includes dentistry information, finger palm print, and a DNA type. However, damage of dead bodies increases with lapse of time from disaster. Now it has passed 1 year and more, and individual identification with finger palm-print and DNA type has been in much more difficult situation. Significance of dentistry for individual identification has been reaffirmed ${ }^{16,17}$. Our results suggest that three-dimensional CT of the hyoid bone is effective for estimation of gender and age in addition to conventional techniques when such a great earthquake occurs in any country of the world.

\section{Conclusion}

Up to now, there is no measurement science research of the hyoid bone which uses a three-dimensional CT imaging. By using MDCT, we can measure and observe the hyoid bone very easily with high accuracy. Existence of lingula should be described in anatomy guidebooks in the future.

The volume of hyoid bone is effective for identification of gender differences at high rates, and ages are able to estimate to some degree from the level of ossification at the connection between hyoid body and greater horns. These results are applied in the forensic medicine. 


\section{References}

1) James E. Anderson, Translated by Shigeru Morita, Toyokazu Kusunoki. Grant's Atlas of Anatomy. Third Japanese edition 1984 by Igaku-Shoin Ltd., Tokyo.

2) Frank H. Netter, Translated by Sadakazu Aiso. Netter Atlas of Human Anatomy. Fifth Edition 2011 by Nankodo Ltd., Tokyo.

3) Mori O, Ogawa T, Oouchi H, Mori T. ANATOMY. Eleven Edition 1998; 95:299-303. By Kanehara Ltd., Tokyo.

4) Takada Y, Miyao T. An uniquely anomalous case of the hyoidean apparatus found in a Male Japanese. Journal of Growth 1987; 26:29-35. (in Japanese)

5) Takada Y, Terashima R, Hanamura H, Izumi M. A fully ossified hyoid apparatus found in a Male Japanese. Aichi Gakuin J. Dent. Sci 2003; 41(2):233-237. (in Japanese)

6) Takada Y, Terashima R, Hanamura H, Izumi M. A fully ossified hyoid apparatus found in Japanese-Presentation of a Third Instance. Aichi Gakuin J. Dent. Sci 2006; 44(3):339-343. (in Japanese)

7) Kamijyo Y. Anatomical Study of the hyoid bone in the Japanese rase. The Journal of the Tokyo Dental College Society 1943; 48(9):497-521. (in Japanese)

8) Haga T. Anthropological Study of Japanese hyoid bone. The Journal of the Tokyo Dental College Society 1956; 56(2):41-48, 53. (in Japanese)
9) Parsons FG. The topography of human hyoid bone. J Ant Physiol 1909; 43(4):279-90.

10) Murata H. Studies on the Hyoid Bone of Japanese People from Viewpoint of Individual Identification. Jpn J Legal Med 1963; 17(4):257-283. (in Japanese)

11) Miller KWP, Walker PL, O'Halloran RL. Age and sex related variation in hyoid bone morphology. J Forensic Sci 1998; 43(6):113843.

12) Gupta A, Kohli A, Aggarwai NK, Banerjee KK. Study of age of fusion of hyoid bone. Legal Med 2008; 10(5):253-6.

13) Shimizu Y, Kanetaka H, Kim YH, Okayama K, Kano M, Kikuchi M. Age related morphological changes in human hyoid bone. Cells Tissues and Organs 2005; 180(3):185-92.

14) Lekšan I, Marcikić M, Nikolić V, radić R, Selthofer R. Morphological classification and sexual dimorphism of hyoid bone: New approach. Coll. Antropol 2005; 29(1):237-242.

15) Kamijyo Y. Oral anatomy (Ed bone). Second edition 1943; 127. (in Japanese)

16) Motomura A, Chiba F, Makino Y, Inokuchi G, Yajima D, Hayakawa $\mathrm{M}$, Iwase $\mathrm{H}$. Current status and problems of the death investigation system in the Great East Japan Earthquake. J. J. Disast. Med 2012; 17(1):191-195. (in Japanese)

17) Someda H, Itabashi J, Kanno A. Victim Identification in the Great East Japan Earthquake - Case Report of SOMA and MINAMISOMA Area -. J. J. Disast. Med 2012; 17(1):200-206. (in Japanese) 